\title{
Ciclopirox Hydroxypropyl Chitosan (HPCH) Nail Lacquer: A Review of Its Use in Onychomycosis
}

Bianca Maria Piraccini · Matilde Iorizzo • André Lencastre •

Pietro Nenoff · Dimitris Rigopoulos

Received: May 25, 2020 / Published online: July 23, 2020

(C) The Author(s) 2020

\begin{abstract}
Ciclopirox 8\% hydroxypropyl chitosan (HPCH) [Marketed in different countries as the following registered (®) brands: Ciclopoli, Fulcare, Kitonail, Myconail, Niogermos, Niogermox, Onytec, Ony-Tec, Polinail, Privex, Rejuvenail] is
\end{abstract}

Digital Features To view digital features for this article go to https://doi.org/10.6084/m9.figshare.12555215.

B. M. Piraccini $(\bowtie)$

Dermatology Unit, Department of Experimental, Diagnostic and Specialty Medicine, Alma Mater Studiorum, University of Bologna, Bologna, Italy e-mail: biancamaria.piraccini@unibo.it

M. Iorizzo

Private Dermatology Practice, Bellinzona, Switzerland

A. Lencastre

Serviço de Dermatologia, Hospital de Santo António dos Capuchos, Centro Hospitalar Universitário de Lisboa Central, Lisbon, Portugal

P. Nenoff

Allergology, Andrology, Tropical and Travel Dermatology (DDA), Laboratory for Medical Microbiology, Partnership Prof. Dr. med. Pietro Nenoff \& Dr. med. Constanze Krüger, Rötha OT Mölbis, Germany

D. Rigopoulos

Dermatology-Venereology, Department of Medicine, School of Health Sciences, National and Kapodistrian University of Athens-A. Sygros Hospital, Athens, Greece the first topical nail lacquer developed using innovative drug formulation technology. It is indicated for the treatment of mild-to-moderate fungal infections of the nails that are caused by dermatophytes and/or other ciclopirox-sensitive fungi, without nail matrix involvement. $\mathrm{HPCH}$ is a patented drug formulation technology for the delivery of active principles into the nails based on a hydrosoluble semisynthetic amino-polysaccharide biopolymer derivative of chitosan. The lacquer acts as a protective barrier against microbiological attack, physical damage and/or aggressive chemicals. Results from in vitro studies suggest that the application of ciclopirox 8\% HPCH nail lacquer improves drug permeation into and/or drug penetration through the nail, relative to the water-insoluble ciclopirox $8 \%$, amorolfine $5 \%$ and efinaconazole $10 \%$ reference lacquers. In addition, in vitro and clinical studies in healthy subjects found that the concentration of ciclopirox reached in subungual fluids after application of ciclopirox 8\% HPCH was sufficient for inhibiting fungal growth. In clinical studies in patients with mild-to-moderate onychomycosis, ciclopirox $8 \% \mathrm{HPCH}$ was found to be more effective than the commercial water-insoluble ciclopirox $8 \%$ and amorolfine 5\% lacquers, as indicated by higher complete cure, response and mycological cure rates at 48 weeks after treatment initiation. Ciclopirox 8\% HPCH has been found to be generally well tolerated, with no treatmentrelated adverse events reported in patients using 
this nail lacquer. Thus, current evidence indicates that ciclopirox 8\% HPCH represents a valuable treatment option for the treatment of patients with onychomycosis.

Keywords: Antifungal; Ciclopirox; Hydroxypropyl chitosan; Onychomycosis

\section{Key Summary Points}

Ciclopirox 8\% hydroxypropyl chitosan (HPCH) is the first topical nail lacquer formulated using the $\mathrm{HPCH}$ drug formulation technology.

This review assesses the efficacy and safety of ciclopirox 8\% $\mathrm{HPCH}$ in the treatment of mild-to-moderate fungal infections of the nails caused by dermatophytes and/or other ciclopirox-sensitive fungi, without nail matrix involvement.

In vitro studies found that the application of ciclopirox 8\% HPCH nail lacquer improved drug permeation into and/or drug penetration through the nail, relative to water-insoluble ciclopirox $8 \%$, amorolfine 5\% and efinaconazole $10 \%$ reference lacquers.

In clinical studies in patients with mild-tomoderate onychomycosis, ciclopirox $8 \%$ $\mathrm{HPCH}$ was found to be more effective than water-insoluble ciclopirox $8 \%$ and amorolfine $5 \%$ commercial lacquers, as indicated by higher complete cure, response and mycological cure rates.

Ciclopirox 8\% HPCH was well tolerated.

\section{INTRODUCTION}

Onychomycosis is a common fungal infection of the nail that affects approximately $4 \%$ of the general population worldwide [1] and accounts for approximately half of all nail infections [2].
The infection can have a significant impact on patient quality of life, causing pain, discomfort and physical impairment [3]. If left untreated, the infection can spread to other nails as well as to other parts of the body [4]. The organisms most commonly associated with onychomycosis include dermatophytes (e.g. Trichophyton spp.), non-dermatophyte moulds (NDMs; e.g. Scopulariopsis brevicaulis, Acremonium spp., Aspergillus spp. and Fusarium spp.) and yeasts (most frequently Candida spp. in finger nails) [5]. Up to $70 \%$ of dermatophyte nail infections are caused by Trichophyton rubrum and T. mentagrophytes, but the prevalence and type of infection vary geographically. Although dermatophytes are the most common infectious organisms responsible for onychomycosis, mixed infections and those caused by NDMs are currently being reported at increasing frequencies, especially in warmer climates. Historically, NDMs as the causative agents of onychomycosis have generally been ignored, especially in the presence of a dermatophyte. Consequently, the treatment of onychomycosis due to NDMs and mixed infection has not been studied as extensively as the treatment of nail infections caused by dermatophytes, which may have implications for successful disease management, particularly recurrences [5].

The aim of treatment in onychomycosis is to eliminate the fungal pathogen, restore the nail and prevent reinfection [6]. Treatment options in Europe include systemic therapy (e.g. terbinafine, itraconazole, fluconazole), topical therapy (e.g. amorolfine and ciclopirox) and combination therapy with systemic and topical antifungals [6, 7]. The choice of therapy depends on the extent and severity of infection, the pathogen responsible, risk of drug interactions or adverse events and success or failure of previous treatment [4]. Systemic therapy is used widely because of its easy accessibility, low cost and high efficacy, but it may be associated with systemic adverse events (AEs) and drug interactions and require laboratory monitoring [6]. Topical therapy is generally recommended for superficial white onychomycosis and early distal and lateral subungual onychomycosis, and when systemic antifungals are contraindicated [7]. Topical antifungals are associated with a low 
risk of systemic AEs and drug interactions [6]; however, the hard keratin and compact nail plate structure of the dorsal nail plate act as a barrier to effective drug delivery via traditional topical formulations, such as creams and ointments $[7,8]$. This has led to the development of nail lacquers, a formulation which improves penetration of the drug through the nail plate [9] while maintaining a proper drug concentration at the nail surface [8]. However, the first medicated nail lacquers contained water-insoluble monoester film-forming agents that have no affinity to keratin and act as occlusive medications, thereby reducing the diffusion of antifungal drugs from subsequent applications through the nail and limiting efficacy [10]. These insoluble films have to be removed frequently using solvents and a nail file, which can damage the nail structure and increase the risk of reinfection [10].

To overcome this limitation, a new technology, based on hydroalcoholic solutions of hydroxypropyl chitosan (HPCH), was developed. HPCH is a water-soluble semi-synthetic derivative of chitosan that acts as a film-forming agent [10]. Ciclopirox 8\% HPCH is the first topical nail lacquer formulated with the $\mathrm{HPCH}$ drug formulation technology. It is indicated for the treatment of mild-to-moderate fungal infections of the nails, caused by dermatophytes and/or other ciclopirox-sensitive fungi, without nail matrix involvement. Here we review the pharmacological profile and clinical efficacy of ciclopirox 8\% HPCH for this indication.

This article is a review of previously conducted studies in line with the updated Good Publishing Practice (GPP-3) guidelines.

\section{CICLOPIROX}

Ciclopirox is a hydroxypyridone antifungal agent with a broad spectrum of activity against dermatophytes (Trichophyton spp., Microsporum spp., Epidermophyton floccosum), yeasts (Candida spp., Malassezia furfur, Cryptococcus neoformans, Saccharomyces cerevisiae) and moulds (e.g. Aspergillus spp., Fusarium solani) $[8,11]$. It has also shown antifungal activity against certain Candida species (e.g. Candida glabrata and krusei) that are frequently resistant to azole antifungal drugs [11]. Ciclopirox has fungicidal and fungistatic activity depending on the concentration and the duration of contact with target organisms [11], as well as sporicidal activity [12]. The in vitro minimum inhibitory concentration (MIC) values of ciclopirox against most dermatophytes, yeasts and moulds are in the range of $0.9-3.9 \mu \mathrm{g} / \mathrm{mL}$ (agar microdilution method) [13].

Ciclopirox has also shown potent antibacterial activity against Gram-negative bacteria (e.g. Pseudomonas aeruginosa, Proteus mirabilis, Escherichia coli, Klebsiella pneumoniae) and Gram-positive bacteria (e.g. Staphylococcus aureus, $\beta$-haemolytic Streptococcus group A, Micrococcus luteus and sedentarius, Corynebacterium minutissimum, Brevibacterium spp. and Corynebacterium spp.), with MIC values ranging from 0.06 to $2.0 \mu \mathrm{g} / \mathrm{mL}$ [14]. Its antibacterial activity has a broader spectrum than that of other antifungal agents [11]. Ciclopirox also exhibits anti-inflammatory effects via inhibition of the arachidonic acid cascade, resulting in the inhibition of synthesis of prostaglandins and leukotrienes in polynuclear granulocytes $[8,14]$.

Unlike most other topical antifungal drugs, which generally act by inhibiting ergosterol, the antifungal activity of ciclopirox is thought to be largely due to iron chelation, which restricts the availability of iron to the fungal cell and inhibits its growth [11, 15]. Ciclopirox also inhibits peroxidases and catalases, which are responsible for the degradation of toxic metabolites in fungal cells, and it targets diverse metabolic (e.g. respiratory) and energy-producing processes in microbial cells [15].

Because of its unique multitarget mechanism of action, ciclopirox has a very low potential for the development of resistance in pathogenic fungi [15]. Ciclopirox has a steep dose-response curve, and small changes in drug dosage may result in considerable variation in antimicrobial response, thereby limiting the development of resistance $[11,14]$. Moreover, irreversible binding of ciclopirox to intracellular structures may prevent the drug from being used as a substrate for resistance pumps, thus maintaining antifungal/antibacterial efficacy in the long-term. 
Indeed, in one study, in vitro ciclopirox did not induce resistance in $T$. rubrum either spontaneously or after prolonged exposure to subinhibitory drug concentrations for several growth generations [16]. In comparison, in the same study the frequency of spontaneous resistance to terbinafine was approximately $10^{-7}$ and to amorolfine and itraconazole was $10^{-9}$; the resistance frequency to terbinafine, amorolfine and itraconazole after prolonged exposure to subinhibitory drug concentrations was $10^{-5}$, $10^{-7}$ and $10^{-8}$, respectively [16].

\section{HYDROXYPROPYL CHITOSAN TECHNOLOGY}

Hydroxypropyl chitosan is a patented drug formulation technology for the delivery of active principles into the nails based on a hydrosoluble semisynthetic amino-polysaccharide biopolymer derivative of chitosan [10] (Fig. 1). This molecule is characterized by high solubility in water, high plasticity and high affinity for keratin, wound-healing activity and high compatibility with human tissues, all properties which contribute to its suitability as a filmforming agent [17].

$\mathbf{a}$
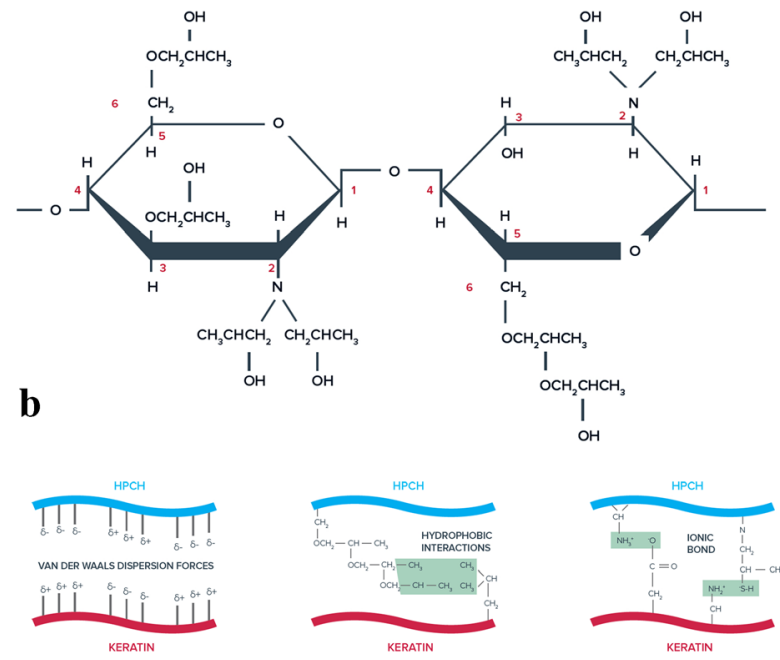

Fig. 1 a Chemical structure of hydroxypropyl chitosan $(\mathrm{HPCH})$ and $\mathbf{b}$ suggested mechanism of adhesion of a $\mathrm{HPCH}$ film on the nail surface
In vitro, $\mathrm{HPCH}$ applied as a hydroalcoholic solution on the surface of bovine hoof slices forms a thin film after evaporation of the solvent [10]. It is thought that the positively charged $\mathrm{HPCH}$ adheres to the negatively charged keratin of the nail and penetrates the nail structure (Fig. 1), filling in ridges, holes and other irregularities $[10,18]$. Being water soluble, the HPCH film is easily removed by washing with water and does not require solvents or abrasives.

In vivo and in vitro studies have shown that the $\mathrm{HPCH}$ film acts as a protective barrier against microbiological attacks, physical damage and/or aggresive chemicals [10, 18]. Abrasion tests on healthy volunteers and bovine hoof slices revealed that application of an HPCH solution protected the nail against abrasion. In a bovine hoof model, nail hardness and tensile strength were significantly $(p<0.001)$ increased after application of a HPCH solution compared with an untreated control sample [19]. In contrast, solutions of $40 \%$ urea and $70 \%$ isopropyl alcohol, which are commonly used for cosmetic or therapeutic purposes, adversely affected nail hardness ( $p<0.001$ vs. control) and tensile strength ( $p$ nonsignificant vs. control) (both nail hardness and tensile strength, $p<0.001$ for $\mathrm{HPCH}$ solution vs. comparators) [19].

In addition, application of a HPCH solution prevented the growth of fungal pathogens in in vitro models of nail infection $[10,19]$. The fungal burden of dermatophytes ( $T$. rubrum or T. mentagrophytes) in bovine hoof slices was lower following treatment with a HPCH-based nail solution compared with the control, as assessed by microscopy at day 7 post-exposure [19]. Furthermore, the growth of T. rubrum was delayed (no colonies at day 5 vs. 3.30-log CFU/g colony count in untreated controls), and the depth of fungal penetration by the two dermatophytes was lower (e.g. penetration depth at day 9: $<25 \mu \mathrm{m}$ vs. $275 \mu \mathrm{m}$ for T. mentagrophytes) in hooves treated with a HPCH nail solution compared with untreated hooves [19]. In contrast, hoof slices treated with urea or isopropyl alcohol showed more fungal penetration at day 7 and a marked increase in infection by day 15 
compared with hoof slices treated with an HPCH solution [19].

Taken together, these results indicate that chemicals, such as urea (used as a nail pretreatment to improve the penetration of antifungals) and isopropyl alcohol (used to remove previously applied solution layers of some nail formulations), may adversely affect the physical characteristics of the nail and increase the risk of fungal infection [19]. In contrast, application of a HPCH-based solution may strengthen the nail and improve the natural barrier against fungal infection [19].

\section{CICLOPIROX 8\% HPCH NAIL LACQUER}

Ciclopirox 8\% HPCH is a patented water-soluble nail lacquer containing an $8 \%$ concentration of ciclopirox and HPCH. It is a transparent solution for topical use on fingernails, toenails and adjacent skin, and is marketed in a 3.3-or 6.6$\mathrm{mL}$ glass bottle with a screw cap that is fitted with a brush [20]. Ciclopirox 8\% HPCH is quick drying (within seconds of application), odourless and invisible after drying and easily removed by washing with water without the need for any solvent to be applied or for nail filing [20].

\section{Preclinical Studies}

\section{Nail Penetration}

Results from in vitro studies suggest that the application of ciclopirox 8\% HPCH nail lacquer improves drug permeation into and/or drug penetration through the nail relative to waterinsoluble reference lacquers. In a recent review, Gupta and colleagues noted that ciclopirox 8\% lacquer was able to penetrate excised human toenail tissue after only one application, with the dorsal nail plate containing the highest concentrations and the lower layer containing the lowest concentrations [5]. With repeated applications, these authors noted that drug levels were more homogenous among the nail layers and reached concentrations much higher than the MICs for dermatophytes [5].
Ciclopirox 8\% HPCH Nail Lacquer Versus Ciclopirox Water-Insoluble Lacquer An in vitro study using a bovine hoof model (a validated model for infected human nails [21]) showed that the permeation/penetration of ciclopirox from ciclopirox 8\% $\mathrm{HPCH}$ was faster than that from a ciclopirox $8 \%$ water-insoluble lacquer (Penlac $®$; Aventis Pharma). The lag time (i.e. time taken by the drug to saturate the membrane) for ciclopirox was shorter with ciclopirox $8 \% \mathrm{HPCH}$ than for the comparator (3.4 vs. $12.5 \mathrm{~h} ; p<0.05$ ) [17]. The diffusive flux value $(J$; i.e. amount of permeant diffusing across the area in time) of ciclopirox at steady state and the percentage of drug retained in the membrane at study end were generally similar between ciclopirox $8 \% \mathrm{HPCH}$ and the waterinsoluble formulation ( 4.7 vs. $3.1 \mu \mathrm{g} / \mathrm{cm}^{2} \mathrm{~h}$ and 11.0 vs. $11.6 \%$, respectively) [17]. Based on these results, the Spanish Summary of Product Characteristics recommends that nails treated with ciclopirox $8 \% \mathrm{HPCH}$ should not be washed for at least $6 \mathrm{~h}$ after application and that the lacquer should be applied in the evening before going to bed [20].

In another study, when ciclopirox 8\% $\mathrm{HPCH}$ and a water-insoluble ciclopirox $8 \%$ lacquer (Penlac) were applied on neutral disks or on bovine hoof membranes and placed on fungal cultures (including T. rubrum and T. mentagrophytes), inhibition rings on bovine hoof membranes soaked with ciclopirox 8\% HPCH were consistently larger than those soaked with ciclopirox water-insoluble lacquer [22], indicating that ciclopirox permeated better from the ciclopirox $8 \% \mathrm{HPCH}$ formulation than from the water-insoluble formulation.

\section{Ciclopirox 8\% HPCH Nail Lacquer Versus Water-Insoluble Amorolfine 5\% Formula- tion Ciclopirox from a $\mathrm{HPCH}$ vehicle pene-} trated hoof membranes more easily and to a greater extent than amorolfine from a waterinsoluble commercial formulation (Loceryl ${ }^{\circledR}$; Galderma International), as evidenced by the former's significantly higher $(p<0.05)$ values for transungual flux $(J: 6.38$ vs. $0.33 \mu \mathrm{g}$ $\left.\mathrm{cm}^{-2} \mathrm{~h}^{-1}\right)$, percentage of permeated drug at $24 \mathrm{~h}\left(\mathrm{Q} \%{ }_{24} \mathrm{~h}: 1.09\right.$ vs. $\left.0.09 \%\right)$ and apparent permeability coefficient $\left(\mathrm{P}_{\mathrm{app}} \times 10^{3}\right.$; i.e. the 
ratio of flux and initial drug concentration: 0.094 vs. $0.008 \mathrm{~cm} \mathrm{~h}^{-1}$ ) [23]. Lag times for ciclopirox and amorolfine did not differ significantly between the solutions (1.31 vs. $1.4 \mathrm{~h})$ [23].

These findings were supported by results from an in vitro study using excised healthy human nails, which showed that drug permeation and penetration from ciclopirox 8\% $\mathrm{HPCH}$ was greater than that from amorolfine $5 \%$ anhydrous commercial formulation (Loceryl), as indicated by greater flux (Fig. 2; J: 33.9 vs. $0.13 \mu \mathrm{g} / \mathrm{cm}^{2}$ per day; $p<0.0001$ ), percentage of drug penetration $\left(Q^{\prime} \%\right.$ on day 7: 2.1 vs. $0.24 \%$ ) and amount of drug penetration and retention values $\left(Q^{\prime}\right.$ on day 7: 0.98 vs. $0.14 \mu \mathrm{g}$ drug/mg nail) [24].

Ciclopirox 8\% HPCH Nail Lacquer Versus Efinaconazole 10\% Topical Solution Ciclopirox permeation and penetration were also greater than that of efinaconazole when two commercial preparations of the drugs were compared using a bovine hoof model [25]. Ciclopirox 8\% $\mathrm{HPCH}$ nail lacquer (Fulcare $\AA$; Menarini) was associated with significantly $(p<0.05)$ greater drug flux (J: 4.9 vs. $0.58 \mu \mathrm{g} / \mathrm{cm}^{2} \mathrm{~h}$ ), shorter lag time ( 1.5 vs. $11.0 \mathrm{~h})$, more permeation through the membrane at $30 \mathrm{~h}\left(\mathrm{Q} \% \%_{30 \mathrm{~h}}: 3.29 \%\right.$ vs. $0.24 \%)$ and greater recovery of $\operatorname{drug}\left(Q^{\prime}: 3.4 \mathrm{vs}\right.$. $0.06 \mu \mathrm{g} / \mathrm{mg}$ membrane) than an efinaconazole $10 \%$ topical solution (Jublia ${ }^{\circledR}$; Valeant Pharma). The $\mathrm{P}_{\text {app }}$ value, which is influenced by the drug's physicochemical characteristics and the type of vehicle, irrespective of drug concentration, was approximately tenfold higher for the ciclopirox formulation than for the efinaconazole formulation $(61.5 \mathrm{vs} 5.8 \mathrm{~cm} / \mathrm{h})$. All differences between the permeation/penetration parameters of the two products were statistically significant $(p<0.05)$ [25].

\section{Antifungal Activity}

In vitro studies showed that application of ciclopirox $8 \% \mathrm{HPCH}$ facilitated fast penetration of the antifungal agent through the nail plate and achieved levels that were sufficient to inhibit fungal replication for prolonged periods $(30 \mathrm{~h})$. This was associated with significantly higher efficacy index values for ciclopirox $8 \%$ HPCH compared with amorolfine 5\% [23, 24]. The Efficacy Index (EI) was calculated as the ratio of drug concentration available at the site of action to the MIC against a selected fungal

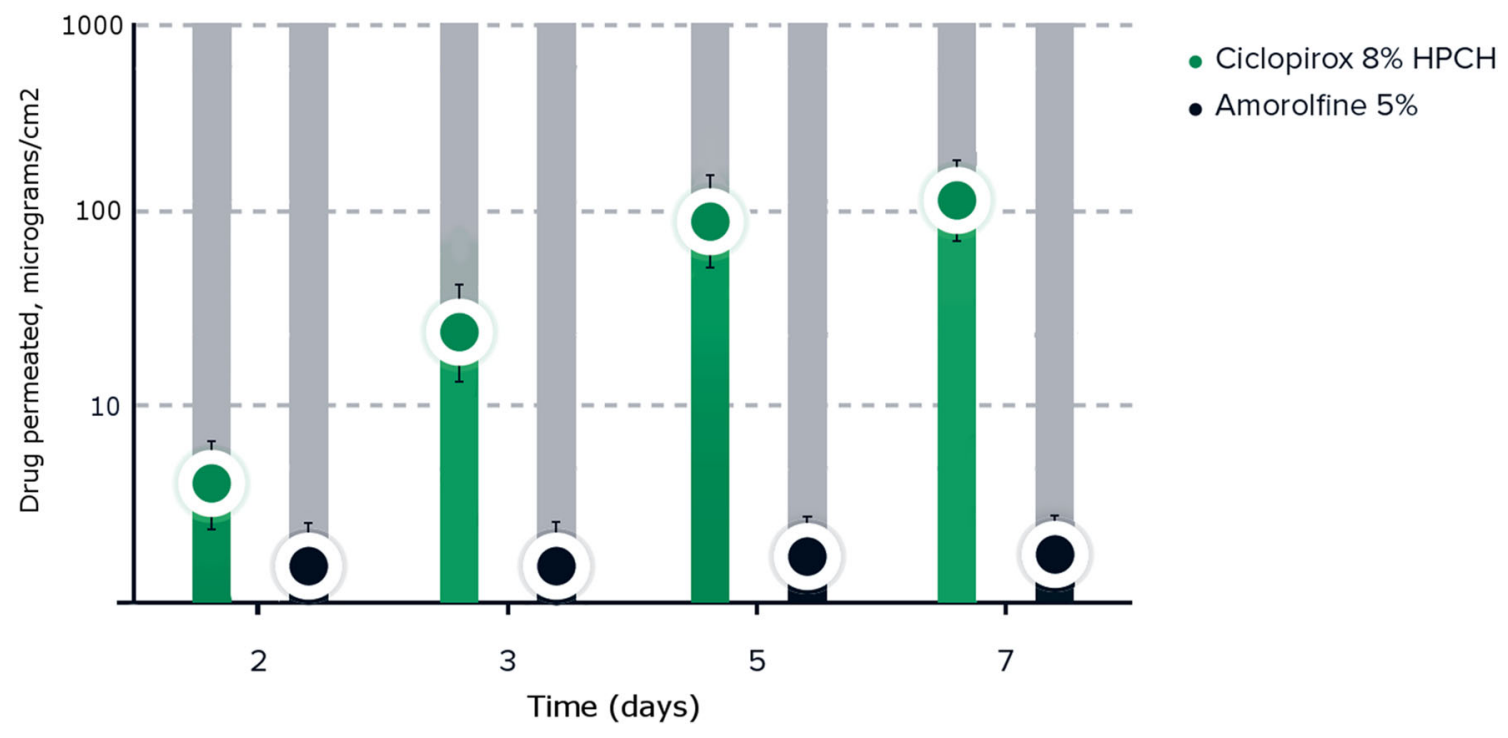

Fig. 2 Amount of ciclopirox or amorolfine permeated through the nail from the ciclopirox $8 \%$ hydroxypropyl chitosan formulation or amorolfine 5\% formulation in vitro. (Adapted from Monti et al. [24]) 
Table 1 In vitro antifungal activity of ciclopirox $8 \%$ hydroxypropyl chitosan formulation

\begin{tabular}{llllll}
\hline Study & \multicolumn{4}{l}{ Efficacy Index $^{\mathbf{a}}$ (CPX vs. MRF) } & \\
& $\begin{array}{l}\text { Trichophyton mentagrophytes } \\
\text { var. } \text { interdigitale }\end{array}$ & $\begin{array}{l}\text { Trichophyton } \\
\text { rubrum }\end{array}$ & $\begin{array}{l}\text { Microsporum } \\
\text { canis }\end{array}$ & $\begin{array}{l}\text { Candida } \\
\text { parapsilosis }\end{array}$ & $\begin{array}{l}\text { Scopulariopsis } \\
\text { brevicaulis }\end{array}$ \\
\hline $\begin{array}{c}\text { Bovine hoof } \\
\text { model [23] }\end{array}$ & 61.3 vs. 32.0 & 61.3 vs. 8.0 & 61.3 vs. 16.0 & 30.6 vs. 1.0 & 30.6 vs. 8.0 \\
$\begin{array}{c}\text { Healthy human } \\
\text { nails [24] }\end{array}$ & 135.6 vs. 5.2 & 135.6 vs. 1.3 & 135.6 vs. 2.6 & 67.8 vs. 0.16 & 67.8 vs. 1.3 \\
\hline
\end{tabular}

a The Efficacy Index is the ratio of the expected drug concentration at the site of action, 1 day after application, to the minimum inhibitory concentration (MIC) against each tested strain. The higher the Efficacy Index, the better the expected efficacy of the in vivo treatment

${ }^{b}$ Mean Efficacy Index of ciclopirox (CPX) and amorolfine (MRF) from CPX 8\% hydroxypropyl chitosan (HPCH) lacquer and water-insoluble MRF 5\% reference lacquer, respectively

strain (higher EI values indicate better expected in vivo efficacy) $[23,24]$. The EI values for ciclopirox from HPCH-based lacquers were higher than those for amorolfine from a commercial water-insoluble lacquer (Loceryl), suggesting potentially superior efficacy of ciclopirox $8 \%$ HPCH against common nail pathogens (Table 1).

Furthermore, ciclopirox 8\% HPCH applied to bovine nail slices was both preventative and curative when tested against $T$. rubrum, $T$. mentagrophytes and M. canis isolated from clinical samples [22]. Another in vitro study assessed the antifungal activity of transungual permeates collected after ciclopirox $8 \% \mathrm{HPCH}$ or efinaconazole $10 \%$ topical solution was applied to bovine hoof membranes [25]. Both tested drugs permeated the bovine hoof membranes, but differences in permeation parameters were observed and appeared to be related to both the active moiety and the formulation. The ciclopirox $8 \% \mathrm{HPCH}$ formulation showed a better affinity than the efinaconazole $10 \%$ solution for the hydrophilic ungual substrate, resulting in increased permeation $(p<0.05)$, with the apparent permeability coefficient for ciclopirox being about tenfold higher than that of efinaconazole. Additionally, in this study two EI values were calculated against T. rubrum, Scopulariopsis brevicaulis and Candida parapsilosis: the EI1 (ratio of drug retained in the hoof
membranes/MIC of each strain) of ciclopirox was similar to that of efinaconazole when the MIC of efinaconazole against T. rubrum was $0.005 \mathrm{mg} / \mathrm{L}$, and higher than that of efinaconazole for $C$. parapsilosis and S. brevicaulis. In the case of the permeation experiments, the EI2 (ratio of drug permeated through the hoof membranes to reach the subungual space/MIC of each strain) of ciclopirox was lower than that of efinaconazole against $T$. rubrum, similar against $S$. brevicaulis and higher against $C$. parapsilosis. In the case of T. rubrum, the higher in vitro intrinsic potency of efinaconazole compared to ciclopirox overcame the gap of lower permeation of efinaconazole from the commercial formulation, compared to ciclopirox $8 \% \mathrm{HPCH}$ [25]. These results suggest that each drug acts in two different ways: ciclopirox may create a depot in the nail and is gradually released over time, acting both in the nail plate and nail bed; in contrast, efinaconazole, which has a low affinity for keratin, mainly exerts its antifungal activity in the nail bed. The two drugs have similar antifungal activity against $T$. rubrum in the nail plate [25]. Finally, in the same study, the frequency of spontaneous in vitro T. rubrum-resistant strains was assessed by broth microdilution assays. Efinaconazole showed a potential for induction of resistance which may limit its efficacy over time, while ciclopirox, which is fungicidal and 
sporicidal, did not show any potential to induce resistance [25].

\section{Clinical Efficacy}

\section{Healthy Subjects}

Application of ciclopirox 8\% HPCH nail lacquer resulted in better drug penetration and higher predicted efficacy than a water-insoluble amorolfine 5\% lacquer (Loceryl) in a randomized, open-label, single-centre, phase 1 study in healthy subjects $(n=24)$ [26]. The subjects in this study applied ciclopirox 8\% $\mathrm{HPCH}$ once daily with a brush and amorolfine 5\% lacquer twice weekly with a spatula, for 28 days. All patients applied one treatment per hand on all fingernails. The amount of ciclopirox and amorolfine from the free edge of the nail was determined at baseline and on days 15 and 25 following treatment initiation. The efficacy of the two formulations was predicted using EI values, which were calculated based on the amount of drug recovered from the nail and the MIC values for T. rubrum and C. parapsilosis. At both time points, the EI values against the two pathogens were significantly higher with ciclopirox 8\% HPCH than with amorolfine 5\%
(Fig. 3). All subjects treated with ciclopirox 8\% HPCH had very high $(\geq 5000 \times$ MIC) or high $(\geq$ 500 to $<5000 \times$ MIC) EI values. Additionally, significant differences favouring ciclopirox $8 \%$ $\mathrm{HPCH}$ versus amorolfine 5\% were found in the number of subjects with very high or high EI values against $T$. rubrum on day $25(p=0.0008)$ and against $C$. parapsilosis on days 15 and 25 ( $p=0.0008$ and $p<0.0001$, respectively) [26].

\section{Patients with Onychomycosis}

Two pivotal randomized studies and a non-interventional study assessed the efficacy of ciclopirox $8 \% \mathrm{HPCH}$ in patients with mild-tomoderate onychomycosis. The randomized studies enrolled Caucasian patients (mean age approx. 50-54 years) with subungual, mild-tomoderate onychomycosis of at least one big toenail (target nail; infected area $\geq 25$ to $100 \%$ [27] or $\geq 25$ to $\leq 75 \%$ ) [28]. Patients with dermatophyte [27] or dermatophyte, yeast or mould [28] infections were included in the studies. Patients enrolled in the non-interventional study were mostly Caucasian (99\%) and had a mean age of 59 years [29].

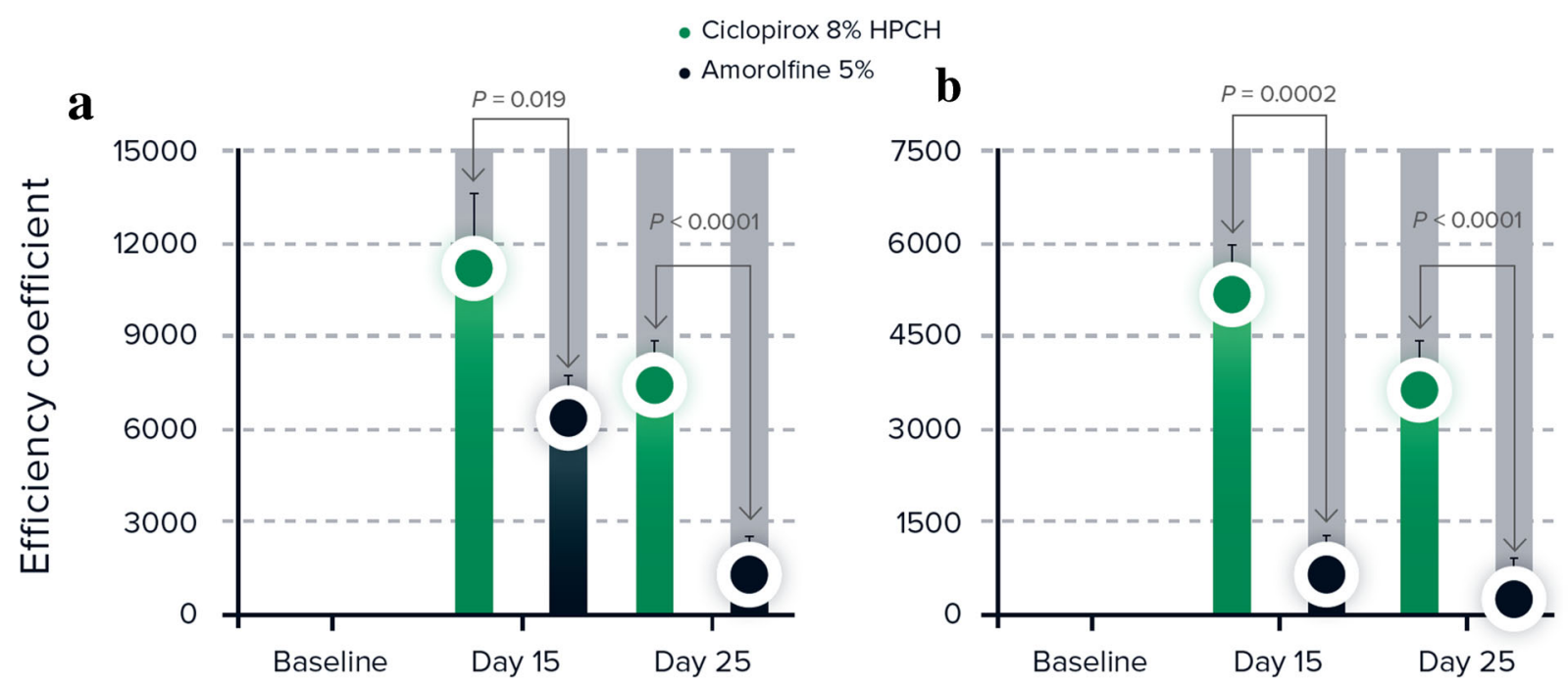

Fig. 3 Efficiency index values against a Trichophyton rubrum and b Candida parapsilosis for ciclopirox and amorolfine after multiple applications of ciclopirox $8 \%$

$\mathrm{HPCH}$ or the reference amorolfine $5 \%$ nail lacquer in healthy subjects. (Adapted from Monti et al. [26]) 
Table 2 Efficacy of ciclopirox 8\% hydroxypropyl chitosan nail lacquer in two randomized studies in patients with distal subungual, mild-to-moderate onychomycosis of at least one big toenail (target nail)

\begin{tabular}{|c|c|c|c|c|c|c|}
\hline $\begin{array}{l}\text { Study design/ } \\
\text { reference }\end{array}$ & $\begin{array}{l}\text { Time } \\
\text { point }\end{array}$ & $\begin{array}{l}\text { Treatment } \\
\text { (no. of ITT } \\
\text { patients) }\end{array}$ & $\begin{array}{l}\text { Complete cure } \\
\text { rate }(\% \text { of } \\
\text { patients })^{\mathrm{a}}\end{array}$ & $\begin{array}{l}\text { Response } \\
\text { rate }(\% \text { of } \\
\text { patients) }\end{array}$ & $\begin{array}{l}\text { Culture conversion } \\
\text { to negative (\% of } \\
\text { patients) }\end{array}$ & $\begin{array}{l}\text { Mycological } \\
\text { cure rate (\% of } \\
\text { patients) }\end{array}$ \\
\hline \multirow{6}{*}{$\begin{array}{l}\text { Randomized, double- } \\
\text { blind study/Baran } \\
\text { et al. [27] }\end{array}$} & \multirow[t]{3}{*}{$\begin{array}{l}\text { Week } \\
48\end{array}$} & $\begin{array}{l}\text { CPX HPCH } \\
(175)\end{array}$ & $5.7^{* \mathrm{c}}$ & $24^{* * *}$ & $89^{* * *}$ & \\
\hline & & $\begin{array}{l}\text { CPX } \\
\text { reference } \\
(185)\end{array}$ & $3.2^{\mathrm{c}}$ & 17.3 & 91 & \\
\hline & & Placebo (94) & $0^{\mathrm{c}}$ & 6.4 & 69 & \\
\hline & \multirow{3}{*}{$\begin{array}{l}\text { Week } \\
60\end{array}$} & СРX НРCH & $12.7^{* * \dagger}$ & $28.7^{* \dagger}$ & 79 & \\
\hline & & $\begin{array}{l}\text { CPX } \\
\text { reference }\end{array}$ & 5.8 & 17.3 & 80 & \\
\hline & & Placebo & 1.3 & 14.7 & 72 & \\
\hline \multirow[t]{2}{*}{$\begin{array}{l}\text { Open-label study/ } \\
\text { Iorizzo et al. [28] }\end{array}$} & \multirow[t]{2}{*}{$\begin{array}{c}\text { Week } \\
48\end{array}$} & $\begin{array}{l}\text { CPX HPCH } \\
\quad(60)\end{array}$ & $35 \ddagger$ & $58.3 \ddagger$ & & $100 \$$ \\
\hline & & MRF (60) & 11.7 & 26.7 & & 82 \\
\hline
\end{tabular}

CPX HPCH Ciclopirox 8\% hydroxypropyl chitosan, MRF Amorolfine, ITT Intent to treat

${ }^{*} p<0.05,{ }^{* *} p<0.005,{ }^{* * *} p<0.0005$ vs. placebo; $;^{\dagger} p<0.05$ vs. CPX reference; ${ }^{*} p<0.001$ vs. MRF $5 \%$

${ }^{a}$ Proportion of patients with negative mycology and $100 \%$ complete clear nail

b Proportion of patients with negative mycology and $\geq 90 \%$ clear nail

c Primary endpoint; results were confirmed at week 52. Superiority of CPX HPCH vs. placebo, and non-inferiority of CPX $\mathrm{HPCH}$ vs. CPX reference was demonstrated as the lower limit of the $95 \%$ confidence interval for the between-group difference was greater than $-10 \%$

Ciclopirox 8\% HPCH Versus Ciclopirox Reference Lacquer One pivotal study $(n=467$ randomized patients with onychomycosis due to dermatophytes) performed a double-blind comparison of the efficacy of ciclopirox $8 \%$ $\mathrm{HPCH}$ with that of placebo (matching vehicle of ciclopirox $8 \% \mathrm{HPCH}$ ), with a third group receiving a water-insoluble commercial ciclopirox 8\% nail lacquer (Penlac) which had a different appearance and required removal before reapplication (and was thus applied in open-label fashion) [27]. Both nail lacquers and placebo were applied once daily to the infected nails for 48 weeks; patients were followed up for an additional 12-week period (week 60). The reference lacquer was removed once a week using solvents and nail filing, while ciclopirox
8\% HPCH and placebo were removed every day by washing with water. The primary endpoint was the complete cure rate (defined as the proportion of patients with negative mycology and $100 \%$ complete clear nail) at week 48 , with results confirmed at week 52 [27].

The study met its primary objective, demonstrating the superiority of ciclopirox $8 \%$ $\mathrm{HPCH}$ to placebo $(p=0.0165)$ and non-inferiority to reference ciclopirox $8 \%$, in terms of the complete cure rate at week 48 (Table 2; endpoints were assessed hierarchically) [27]. At week 60 , the complete cure rate in patients using ciclopirox $8 \% \mathrm{HPCH}$ was significantly $(p<0.05)$ higher by $119 \%$ than in patients using the reference lacquer. The increase in cure rate from week 48 to week 60 may be attributed 
to the continued growth of healthy nail after completion of treatment. The response rate with ciclopirox 8\% HPCH also increased (66\% higher) after treatment completion and was significantly $(p<0.05)$ higher than the response rate with reference lacquer at week 60 (Table 2) [27].

In this study, the ciclopirox nail concentration in subjects treated with ciclopirox 8\% $\mathrm{HPCH}$ for 12 weeks was high $(26.9 \mu \mathrm{g} / \mathrm{mg})$ and remained elevated throughout the treatment period. Moreover, $93 \%$ of the samples achieved high $(\geq 1000 \times$ the MIC for $T$. rubrum) and $84 \%$ achieved very high $(\geq 10,000 \times$ the MIC for $T$. rubrum) concentrations in the nails, confirming the good penetration of ciclopirox into the nail plate [30].

A post hoc subgroup analysis that excluded patients with more severe disease at baseline (i.e. $>50 \%$ nail involvement; $n=302$ ) supported the findings of the primary analysis [31]. At week 60, patients in this subgroup using ciclopirox $8 \% \mathrm{HPCH}$ had higher rates than those using the ciclopirox 8\% reference lacquer and placebo in terms of complete cure (15.1 vs. 5.8 and $1.3 \%$, respectively; both $p<0.05)$, response (34.5 vs. 20.8 and $20.6 \%$, respectively; $p<0.05$, vs. reference) and culture conversion to negative ( 82.4 vs. 75 and $76.2 \%$, respectively) [31]. Moreover, the complete cure, response, and culture conversion to negative rates in the post hoc analysis subgroup of patients treated with ciclopirox 8\% HPCH appeared to be higher than the rates in the overall population $(19,20$ and $4 \%$ higher, respectively, at week 60 ), suggesting that disease severity may be a predictive factor for responsiveness [31].

\section{Ciclopirox 8\% HPCH Versus Amorolfine 5\%}

Lacquer The second pivotal study $(n=120$ evaluable patients with onychomycosis due to dermatophytes or yeasts or NDMs) compared the efficacy of ciclopirox 8\% HPCH with a commercial amorolfine 5\% nail lacquer (Loceryl) [28]. Ciclopirox 8\% HPCH was applied once daily and amorolfine 5\% was applied twice a week for 48 weeks. After only 8 weeks the percentage of negative cultures was significantly higher in the ciclopirox 8\% HPCH group compared with the amorolfine 5\% group [36.2 vs.
$13.2 \% ; p=0.002$ ) (data on file)]. At week 48, patients using ciclopirox 8\% HPCH had significantly $(p<0.001)$ higher complete cure (a composite of negative results from $\mathrm{KOH}$ (potassium hydroxide) microscopic examination and negative culture for fungal pathogens with no residual clinical involvement), response and mycological cure rates than patients using amorolfine 5\% (key efficacy outcomes; Table 2). The estimated numbers needed to treat to achieve one complete cure with ciclopirox 8\% HPCH and amorolfine 5\% were 3 and 11 , respectively, and the non-overlapping 95\% confidence intervals (CIs) confirmed that this difference is statistically significantly in favour of ciclopirox [28].

Ciclopirox 8\% HPCH in Patients Who Failed to Respond to Amorolfine A non-interventional study $[n=70$ full analysis set (FAS) patients with onychomycosis due to dermatophytes, yeasts and NDMs] assessed the efficacy of ciclopirox $8 \% \mathrm{HPCH}$ once daily for the treatment of onychomycosis in patients who had failed to respond to previous treatment with amorolfine $5 \%$ twice weekly for $\geq 6$ months [29]. Successful results for the primary endpoint (negative microscopy in the $\mathrm{KOH}$ test at week 24) were achieved in 41 of 70 subjects $(58.6 \%$ of the FAS; $p<0.0001)$. In addition, $21.4 \%$ of patients achieved a response (i.e. mycological cure and $>90 \%$ clear nail) and $10.7 \%$ of patients achieved complete cure (i.e. mycological cure and $100 \%$ complete clear nail). Taken together, these results suggest that treatment with ciclopirox 8\% HPCH may be an option for patients who fail to respond to amorolfine therapy [29].

\section{Systematic Reviews}

Two systematic reviews of treatments for fungal nail infections have been published in recent years [32, 33]. In the first of these, Ferrari reported that, although benefits are modest, topical ciclopirox was the best topical preparation for treating toenail infections, concluding that no clinically important results were found from randomized controlled trials of other topical agents such as amorolfine, butenafine, 
fluconazole, ketoconazole, terbinafine and tioconazole [32].

In the most recent systematic review, the Cochrane Skin Group evaluated topical drugs (ciclopirox, efinaconazole, luliconazole and tavaborole) in individuals with toenail onychomycosis [33]. In the case of amorolfine, and although this drug was used as a comparator in some of the included trials, the systematic review was unable to assess the quality of the evidence due to the lack of any randomized controlled trials conducted or published that included amorolfine as the intervention of interest [33]. The authors concluded that while the overall evidence supports the use of topical therapies, complete cure rates were relatively low. In the case of ciclopirox 8\% $\mathrm{HPCH}$, there was moderate-quality evidence (GRADE category) from two studies $(n=490)$ showing that it was probably more effective than comparators such as amorolfine 5\% and water-insoluble ciclopirox $8 \%$ in producing a complete cure [relative risk (RR) 2.43, 95\% CI 1.32-4.48), but there was probably little or no difference between the treatments with respect to mycological cure (RR 1.08, 95\% CI 0.85 to 1.37) [33].

\section{TOLERABILITY}

Ciclopirox 8\% HPCH was generally well tolerated in pivotal studies in patients with mild-tomoderate onychomycosis, with no treatmentrelated AEs reported in patients using ciclopirox $8 \% \mathrm{HPCH}[5,27,28]$.

In the study comparing ciclopirox $8 \% \mathrm{HPCH}$ with water-insoluble reference ciclopirox $8 \%$ nail lacquer and placebo, treatment-emergent AEs occurred in approximately $23 \%$ of patients in the safety population $(n=466)$ across all groups. In $1.1 \%$ of patients, AEs were considered to be probably, possibly or definitely related to the treatment [27]. No patients in the ciclopirox $8 \%$ HPCH group compared with two patients in the reference ciclopirox $8 \%$ group and three patients in the placebo group had treatmentrelated AEs, none of which were serious or severe or led to treatment discontinuation. Objective signs and symptoms occurred less frequently with ciclopirox 8\% HPCH than with reference ciclopirox $8 \%$ or placebo ( 2.8 vs. 8.6 and $7.2 \%$ signs, respectively; 7.8 vs. 16.0 and $12.4 \%$ symptoms, respectively). The most common sign in the ciclopirox $8 \% \mathrm{HPCH}$ group was minimal erythema (2.2 vs. 6.4 and $3.1 \%$ in the reference ciclopirox and placebo groups, respectively), and the most common symptoms were itching ( 2.8 vs. 1.6 and $7.2 \%$, respectively) and burning (2.8 vs. 10.7 and $4.1 \%$, respectively). No treatment-related systemic AEs were reported in any group [27].

In the study comparing ciclopirox $8 \% \mathrm{HPCH}$ with amorolfine $5 \%$ nail lacquer, no patient in either treatment group reported a serious, severe or treatment-related $\mathrm{AE}$ or any $\mathrm{AE}$ that resulted in permanent treatment discontinuation [28]. In patients who failed to respond to amorolfine, no AEs were reported during the 24-week observational period of this non-interventional study.

Pharmacovigilance data collected since ciclopirox 8\% HPCH was first introduced in 2008 have not led to any relevant change in the tolerability and safety texts of the approved Summary of Product Characteristics, after almost 9 million patients have received the product.

\section{CONCLUSIONS}

Ciclopirox $8 \% \mathrm{HPCH}$ is the first topical ciclopirox nail lacquer formulated with the patented $\mathrm{HPCH}$ drug formulation technology. HPCH acts as a protective barrier against microbiological attacks and improves nail permeation and penetration of ciclopirox. Ciclopirox $8 \% \mathrm{HPCH}$ is generally well tolerated and more effective than water-insoluble ciclopirox $8 \%$ or amorolfine $5 \%$ nail lacquers, providing a valuable option for the treatment of mild-to-moderate onychomycosis.

\section{ACKNOWLEDGEMENTS}

Funding. This review was supported by an educational grant from Almirall, S.A., 
Barcelona, Spain. The Rapid Service Fees were funded by Almirall, S.A., Barcelona, Spain.

Medical Writing Assistance. Medical writing support was provided by Sohita Dhillon on behalf of Content Ed Net (Spain). This assistance was funded by Almirall, S. A.

Authorship. All named authors meet the International Committee of Medical Journal Editors (ICMJE) criteria for authorship for this article, take responsibility for the integrity of the work as a whole, and have given their approval for this version to be published.

Disclosures. Bianca Maria Piraccini has worked as a consultant for Pierre Fabre-Ducray, ISDIN, Giuliani and Almirall. Matilde Iorizzo has nothing to disclose. André Lencastre has worked as a consultant for Almirall. Pietro Nenoff has received lecture fees from Almirall Hermal, Beiersdorf, Galderma, MSD and Pfizer; and is a member of Expert's Board on Loceryl nail lacquer of Galderma. Dimitris Rigopoulos is a speaker for and on the advisory board of Leo, Abbvie, Janssen, Genesis, Sanofi and Novartis.

Compliance with Ethics Guidelines. This article is a review of previously conducted studies in line with the updated Good Publishing Practice (GPP-3) guidelines.

Open Access. This article is licensed under a Creative Commons Attribution-NonCommercial 4.0 International License, which permits any non-commercial use, sharing, adaptation, distribution and reproduction in any medium or format, as long as you give appropriate credit to the original author(s) and the source, provide a link to the Creative Commons licence, and indicate if changes were made. The images or other third party material in this article are included in the article's Creative Commons licence, unless indicated otherwise in a credit line to the material. If material is not included in the article's Creative Commons licence and your intended use is not permitted by statutory regulation or exceeds the permitted use, you will need to obtain permission directly from the copyright holder. To view a copy of this licence, visit http://creativecommons.org/licenses/by$\mathrm{nc} / 4.0 /$.

\section{REFERENCES}

1. Sigurgeirsson B, Baran R. The prevalence of onychomycosis in the global population: a literature study. J Eur Acad Dermatol Venereol. 2014;28: 1480-91.

2. Piraccini BM, Alessandrini A. Onychomycosis: a review. J Fungi (Basel). 2015;1:30-433.

3. Gupta AK, Mays RR. The impact of onychomycosis on quality of life: a systematic review of the available literature. Skin Appendage Disord. 2018;4: 208-16.

4. Christenson JK, Peterson GM, Naunton M, et al. Challenges and opportunities in the management of onychomycosis. J Fungi (Basel) 2018;4(3):87. https://doi.org/10.3390/jof4030087.

5. Gupta AK, Stec N, Summerbell RC, et al. Onychomycosis: a review. J Eur Acad Dermatol Venereol. 2020; 182(2):287-99.

6. Lipner SR, Scher RK. Onychomycosis: treatment and prevention of recurrence. J Am Acad Dermatol. 2019;80:853-67.

7. Ameen M, Lear JT, Madan V, Mohd Mustapa MF, Richardson M. British Association of Dermatologists' guidelines for the management of onychomycosis 2014. Br J Dermatol. 2014;171:937-58.

8. Tabara K, Szewczyk AE, Bienias WA, et al. Amorolfine vs ciclopirox-lacquers for the treatment of onychomycosis. Postepy Dermatol Alergol. 2014;32:40-5.

9. Thatai P, Sapra B. Transungual delivery: deliberations and creeds. Int J Cosmet Sci. 2014;36: 398-411.

10. Sparavigna A, Setaro M, Frisenda L. Physical and microbiological properties of a new nail protective medical device. J Plastic Dermatol. 2008;4:5-12.

11. Subissi A, Monti D, Togni G, Mailland F. Ciclopirox: recent nonclinical and clinical data relevant to its use as a topical antimycotic agent. Drugs. 2010;70: 2133-52.

12. Seidl HP, Jackel A, Muller J, Schaller M, Borelli C, Polak A. Sporicidal effect of amorolfine and other antimycotics used in the therapy of fungal nail infections. Mycoses. 2015;58:610-9. 
13. Jue SG, Dawson GW, Brogden RN. Ciclopirox olamine $1 \%$ cream. A preliminary review of its antimicrobial activity and therapeutic use. Drugs. 1985;29:330-41.

14. Gupta AK, Plott T. Ciclopirox: a broad-spectrum antifungal with antibacterial and anti-inflammatory properties. Int J Dermatol. 2004;43(Suppl 1): 3-8.

15. Bohn M, Kraemer KT. Dermatopharmacology of ciclopirox nail lacquer topical solution $8 \%$ in the treatment of onychomycosis. J Am Acad Dermatol. 2000;43(Suppl 4):S57-69.

16. Ghelardi E, Celandroni F, Gueye SA, et al. Potential of ergosterol synthesis inhibitors to cause resistance or cross-resistance in Trichophyton rubrum. Antimicrob Agents Chemother. 2014;58:2825-9.

17. Monti D, Saccomani L, Chetoni P, Burgalassi S, Saettone MF, Mailland F. In vitro transungual permeation of ciclopirox from a hydroxypropyl chitosan-based, water-soluble nail lacquer. Drug Dev Ind Pharm. 2005;31:11-7.

18. Chimenti S, Difonzo E, Aste N, Frisenda L, Caserini $\mathrm{M}$. The protective efficacy of a new hydroxypropyl chitosan-based medical device in subjects at risk of onychomycosis. J Plastic Dermatol. 2013;9:185-9.

19. Ghannoum MA, Long L, Isham N, et al. Ability of hydroxypropyl chitosan nail lacquer to protect against dermatophyte nail infection. Antimicrob Agents Chemother. 2015;59:1844-8.

20. Ciclopirox $8 \%$ HPCH (Ony-Tec ${ }^{\circledR}$; Almirall) Spanish Summary of Product Characteristics; (2020). https:/cima.aemps.es/cima/dochtml/ft/72143/FT_ 72143.html

21. Monti D, Saccomani L, Chetoni P, Burgalassi S, Tampucci S, Mailland F. Validation of bovine hoof slices as a model for infected human toenails: in vitro ciclopirox transungual permeation. $\mathrm{Br} \mathrm{J}$ Dermatol. 2011;165:99-105.

22. Togni G, Mailland F. Antifungal activity, experimental infections and nail permeation of an innovative ciclopirox nail lacquer based on a watersoluble biopolymer. J Drugs Dermatol. 2010;9: 525-30.

23. Monti D, Saccomani L, Chetoni P, et al. Hydrosoluble medicated nail lacquers: in vitro drug permeation and corresponding antimycotic activity. Br J Dermatol. 2010;162:311-7.

24. Monti D, Tampucci S, Chetoni P, Burgalassi S, Mailland F. Ciclopirox vs amorolfine: in vitro penetration into and permeation through human healthy nails of commercial nail lacquers. J Drugs Dermatol. 2014;13:143-7.

25. Monti D, Mazzantini D, Tampucci S, et al. Ciclopirox and efinaconazole transungual permeation, antifungal activity, and proficiency to induce resistance in Trichophyton rubrum. Antimicrob Agents Chemother. 2019;63(10):e00442-e519. https://doi.org/10.1128/AAC.00442-19.

26. Monti D, Herranz U, Dal Bo L, Subissi A. Nail penetration and predicted mycological efficacy of an innovative hydrosoluble ciclopirox nail lacquer vs a standard amorolfine lacquer in healthy subjects. J Eur Acad Dermatol Venereol. 2013;27: e153-e158158.

27. Baran R, Tosti A, Hartmane I, et al. An innovative water-soluble biopolymer improves efficacy of ciclopirox nail lacquer in the management of onychomycosis. J Eur Acad Dermatol Venereol. 2009;23:773-81.

28. Iorizzo M, Hartmane I, Derveniece A, Mikazans I. Ciclopirox 8\% HPCH nail lacquer in the treatment of mild-to-moderate onychomycosis: a randomized, amorolfine controlled study using a blinded evaluator. Skin Appendage Disord. 2016;1:134-40.

29. Vanscheidt W, Schalla W. Ciclopirox HPCH nail lacquer after failure of topical treatment with amorolfine. J Dermatol Clin Res. 2015;3:1045.

30. Baran R, Mailland F. Traitement de l'onychomycose avec un nouveau vernis antifongique : corrélation entre efficacité et concentrations unguéales. Ann Dermatol Vénéréol. 2008;135S:A267.

31. Piraccini BM, Tosti A. Ciclopirox hydroxypropyl chitosan: efficacy in mild-to-moderate onychomycosis. Skin Appendage Disord. 2018;5:13-9.

32. Ferrari J. Fungal toenail infections. Am Fam Phys. 2015;92:132-3.

33. Foley K, Gupta AK, Versteeg S, Mays R, Villanueva E, John D. Topical and device-based treatments for fungal infections of the toenails. Cochrane Database Syst Rev. 2020;1:CD012093. https://doi.org/ 10.1002/14651858.CD012093.pub2. 